\title{
Analysis of Induction and Establishment of Dwarf Bunt of Wheat Under Marginal Climatic Conditions
}

Blair J. Goates, USDA-ARS, Aberdeen, ID; Gary L. Peterson, USDA-ARS, Frederick, MD; Robert L. Bowden, USDA-ARS, Manhattan, KS; and Larry D. Maddux, Kansas State University, Topeka

\begin{abstract}
Goates, B. J., Peterson, G. L., Bowden, R. L., and Maddux, L. D. 2011. Analysis of induction and establishment of dwarf bunt of wheat under marginal climatic conditions. Plant Dis. 95:478-484.

Dwarf bunt caused by Tilletia contraversa is a disease of winter wheat that has a limited geographic distribution due to specific winter climate requirements. The pathogen is listed as a quarantine organism by several countries that may have wheat production areas with inadequate or marginal climate for the disease-in particular the People's Republic of China. Field experiments were conducted in the United States in an area of Kansas that is a climatic analog to the northern winter wheat areas of China to evaluate the risk of disease introduction into such areas. The soil surface of four replicate $2.8 \times 9.75 \mathrm{~m}$ plots, planted with a highly susceptible cultivar, was inoculated with six teliospore concentrations ranging from 0.88 to 88,400 teliospores $/ \mathrm{cm}^{2}$. A single initial inoculation was done in each of three nurseries planted during separate seasons followed by examination for disease for 4 to 6 years afterward. Any diseased spikes produced were crushed and returned to

ing all six seasons. In two nurseries, the disease was induced at trace levels at the three highest inoculation rates. Disease carryover to the second year occurred during one year in one nursery in plots at the highest inoculation rate, but no disease occurred the following three seasons. A duplicate nursery planted in a disease conducive area in Utah demonstrated that the highest rate of inoculum used in the experiments was sufficient to cause almost $100 \%$ infection. This study demonstrated that in an area with marginal climatic conditions it was possible to induce transient trace levels of dwarf bunt, but the disease was not established even with a highly susceptible cultivar and high levels of inoculum. Our results support the conclusions of the 1999 Agreement on U.S.-China Agricultural Cooperation which set a tolerance for teliospores in grain, and supports the Risk Assessment Model for Importation of United States Milling Wheat Containing T. contraversa.
\end{abstract} the plots where they were produced. One nursery had no disease dur-
Dwarf bunt of wheat, caused by the smut fungus Tilletia contraversa Kühn, converts kernels into spherical sori filled with dark teliospores. The disease is initiated during winter when soilborne teliospores germinate at the soil surface and eventually produce hyphae that infect winter wheat seedlings. Teliospores are longlived and can retain viability in soil under natural conditions for at least 10 years (14). Significant incidence of dwarf bunt is dependent on a relatively high concentration of teliospores in the soil (6) and continuous snow cover for several weeks in conjunction with relatively mild winter temperatures. Continuous snow cover insulates the soil surface and provides a long period of stable cool temperature and high relative humidity that is required for teliospore germination and infection (14). These essential climatic factors have apparently limited the worldwide distribution of dwarf bunt (3) and prevented the spread of the disease from its historical boundaries in the United States (13) despite unrestricted movement of teliospore-contaminated seed and grain. In the United States, dwarf bunt is under excellent control with resistant cultivars (5) and seed treatment fungicides containing difenoconazole $(4,9,12)$

Corresponding author: Blair J. Goates, E-mail: Blair.Goates@ars.usda.gov

Kansas Agricultural Experiment Station Contribution No. 10-256-J.

The use of trade, firm, or corporation names in this publication is for the information and convenience of the reader. Such use does not constitute an official endorsement or approval by the United States Department of Agriculture or the Agricultural Research Service of any product or service to the exclusion of others that may be suitable.

Accepted for publication 19 December 2010.

doi:10.1094/PDIS-10-10-0732

This article is in the public domain and not copyrightable. It may be freely reprinted with customary crediting of the source. The American Phytopathological Society, 2011. that are utilized in the limited areas of the United States where the disease has the potential to occur regularly.

Dwarf bunt is of minor significance to overall wheat production in the United States and elsewhere. However, 16 countries-Algeria, Brazil, Canada, Chile, People's Republic of China (PRC), Czech Republic, India, Macedonia, Morocco, New Zealand, Paraguay, Poland, Slovakia, South Africa, Tunisia, and Turkey-list varying import restrictions for grain contaminated with $T$. contraversa. The PRC was greatly concerned about the potential introduction and establishment of dwarf bunt in their major winter wheat production areas and therefore maintained a 35-year embargo on U.S. wheat originating from the Pacific Northwest. However, in 1999 an agricultural trade agreement between the United States and the PRC removed the embargo and established a tolerance level for $T$. contraversa teliospores in grain shipments (2). The agreement was supported by a USDA dwarf bunt risk assessment model which concluded that establishment of dwarf bunt in the major winter wheat region of the PRC via the importation of U.S. grain would be highly unlikely because of the low levels of teliospores observed in U.S. grain and the absence of a diseaseconducive environment (11). A portion of the risk assessment model was based on extensive field experiments that determined the relationship between inoculum density and disease development in disease-conducive areas of the United States (6).

The work presented here was conducted to examine the risk of establishment of dwarf bunt in the PRC North China Plain or other areas of the world that have marginal climate for dwarf bunt. A location in Kansas was identified that is a climatic analog to winter wheat areas of the PRC in order to evaluate the potential risk of disease introduction. Logan, UT was chosen as a disease conducive area to compare with the results in Kansas.

\section{Materials and Methods}

Research sites. Potential research sites in the United States that were similar in climate to the North China Plain were evaluated by comparing more than 18 years of data collected and transmitted to 
global data centers throughout the United Nations World Meteorological Organization's telecommunications network. Comparisons included mean monthly temperatures (Fig. 1) and precipitation (Fig. 2) during the growing season from Zhengzhou, Jinan, Wuhu, and Beijing in PRC, and Topeka, KS, Lubbock, TX, and Mutual, $\mathrm{OK}$ in the United States. The temperature profiles during the growing season were similar for all seven regions. There was more variability in precipitation with higher levels during the growing season in Kansas and Wuhu. Based on the climatic similarities and the availability of research support, the Kansas River Valley Experiment Field at Rossville was chosen for the study. Initial inoculation of separate adjacent large field plots at the location in three successive years was followed by several years of replanting with a susceptible cultivar and monitoring for disease. Experiments were conducted in Kansas beginning in the fall of 2001 and continued annually through the 2006-2007 winter wheat growing season. Dwarf bunt has never been reported at the site or anywhere else in Kansas.

An identical experiment was conducted during 2000-2001 at a site near Logan, which was chosen as a disease-conducive area to compare with the results in Kansas. This location has some of the most reliable disease conducive winter climate of anywhere in the United States where dwarf bunt occurs and has been utilized for over 30 years for dwarf bunt disease screening nurseries.

Environmental monitoring. Starting at planting and continuing until harvest, relative humidity, and air and soil surface temperatures were recorded hourly using a HOBO Pro Series data logger and a U22-001 temperature logger (Onset Computer Corp., Pocasset, MA). Soil moisture was measured at a depth of $5 \mathrm{~cm}$ with a ML2 ThetaProbe/THLog4, (Dynamax, Houston, TX). Soil surface temperature data from 25 September through 15 April was used to estimate the presence and duration of snow cover. As with the dwarf bunt Geophytopathological Model used in the T. contraversa risk model (11), the presence of snow was correlated to temperatures at the time of a precipitation event and the time the soil temperature remained at freezing or below. Precipitation events were obtained from the Kansas State Research and Extension weather station at the research site. In addition, snow cover at the Logan site was obtained from records from the Utah State University Agricultural Experiment Station.

Plant culture and soil inoculation. The hard red winter wheat cultivar Cheyenne (PI 192268), which is highly susceptible to dwarf bunt, was used for the experiments. Cheyenne is commonly utilized as a positive control in inoculated dwarf bunt disease screening nurseries to monitor disease pressure, and can have up to $100 \%$ diseased spikes in years with ideal climatic conditions during winter.

Each season, nurseries for the initial inoculation treatments were planted into an area $21 \times 107 \mathrm{~m}$ during early to mid-October with a small grain drill. Seed was planted at a rate of $67 \mathrm{~kg} \mathrm{ha}^{-1}$ and ap-

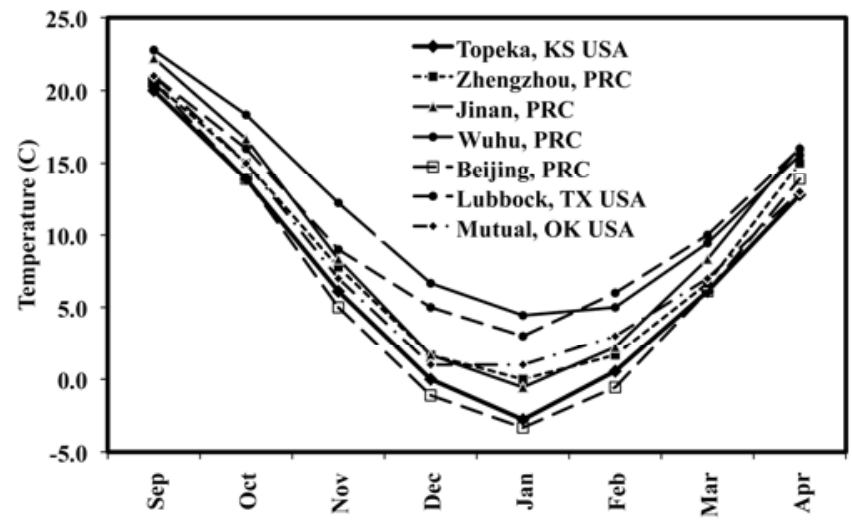

Fig. 1. Comparison of mean monthly (1990 to 2000) temperatures for several principle winter wheat growing regions in the United States and the People's Republic of China. proximately $2 \mathrm{~cm}$ deep with rows spaced $25 \mathrm{~cm}$ apart in five eightrow strips separated from each other by $1.5 \mathrm{~m}$. Planting at this time typically produces seedlings at approximately the three-leaf stage when they become dormant during early winter. Plants seeded at such shallow depth and that are at the one- to three-leaf growth stage going into winter dormancy are particularly susceptible to infection $(7,8,10)$.

After planting, 24 individual plots $2.8 \mathrm{~m}$ wide $\times 9.75 \mathrm{~m}$ long that each contained eight $9.75-\mathrm{m}$-long rows were delimited for inoculation treatments. The plots were separated from each other by at least $1.5 \mathrm{~m}$ and arranged in the nursery three plots wide and eight plots long to accommodate six inoculation treatments arranged in four replicated randomized blocks. Each inoculation treatment plot was enclosed with a 61-cm-high fence made of 1-cm-thick plywood placed about $5 \mathrm{~cm}$ into the soil to prevent movement of inoculum between plots. The fence was supported with $2.5-\mathrm{cm}$ angle iron posts that were screwed to the plywood. Fences were constructed only during the single year each of the nurseries was initially inoculated, and the plots were left open during the following seasons. The location of each plot was recorded with distance measurements from permanent field markers.

Immediately after planting and fence construction, plots were sprayed with $800 \mathrm{ml}$ of a water suspension of teliospores at the rates of $0,0.88,8.84,88.4,884$, or 8,840 teliospores $/ \mathrm{cm}^{2}$ using a Matur plot sprayer (Matur International, Corvallis, OR). In addition, four $2.8 \times 2.8 \mathrm{~m}$ fenced eight-row plots were spaced along the length of the nursery and then sprayed with 88,400 teliospores $/ \mathrm{cm}^{2}$ to serve as a positive control. Previous experience with screening nurseries over many years has indicated that disease cannot be increased by inoculum levels above this rate (B. J. Goates, unpublished). Plots were sprayed sequentially from low to high teliospore concentrations beginning with the water control. The fences were initially left open at one end to accommodate the sprayer, and were closed after spraying. The inoculum consisted of teliospores of a broad composite of isolates of $T$. contraversa originating from throughout the northwestern United States that is used for disease resistance screening nurseries. Diseased spikes collected in 2000 from the Logan dwarf bunt screening nursery were used as inoculum for all nurseries. Teliospore inoculum was prepared by coarsely grinding bunted spikes with a hand-operated grinder and then sieving spores through a $53-\mu \mathrm{m}$ screen. Teliospores were stored at $5^{\circ} \mathrm{C}$ prior to inoculation to maintain a high level of viability. Teliospores retain a high level of viability for more than 10 years even when stored at room temperature.

Three nursery sites were selected at the Rossville, KS location in adjacent fields separated from each other by a minimum of $20 \mathrm{~m}$ One site was seeded and inoculated in 2001, the second in 2002, and the third in 2003 during mid-October. Each nursery site was inoculated only once during the experiments. The seasons follow-

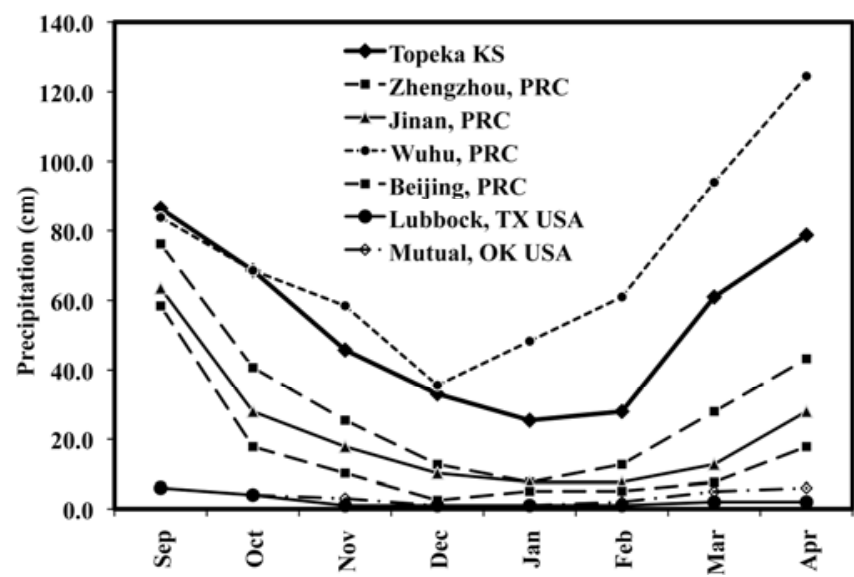

Fig. 2. Comparison of mean monthly (1990 to 2000) precipitation for several principle winter wheat growing regions in the United States and the People's Republic of China. 
ing the initial inoculation, Cheyenne was planted as described previously into the entire $21 \times 107 \mathrm{~m}$ nursery area of prior seasons, but without inoculation, to monitor the effect of residual initial inoculum, or inoculum from diseased plants, if any were produced. Each site was planted up to the 2006-2007 season. Thus, the 2001, 2002 , and 2003 inoculated nurseries were examined for disease for a total of 6,5 , and 4 years, respectively. Between crops, the fields were cultivated and remained fallow.

The duplicate nursery located at Logan was seeded with Cheyenne and inoculated during the fall of 2000 and was monitored only during the 2000-2001 season. This nursery was fumigated prior to planting to rid the soil of teliospores naturally present in the field. A $21 \times 107 \mathrm{~m}$ area was covered with a 6-mil-thick plastic tarp, and then the nursery was fumigated with $98 \%$ methyl bromide gas at the rate of $0.91 \mathrm{~kg} / 30 \mathrm{~m}^{2}$ prior to planting. The fumigant was injected beneath the tarp at approximately 6-m intervals around the perimeter of the tarp. A plastic pipe frame was placed beneath the tarp to support it above the soil surface to aid distribution of the fumigant. The field was fumigated on 25 September 2000 and then fumigated again, at the same rate, 4 days later. On 4 October, the tarp was removed and the nursery was seeded, fenced, and then inoculated on 6 October in the same manner as described for the Kansas experiments. The inoculum concentration plots were located a minimum of $4.6 \mathrm{~m}$ inside the fumigated area. A 4row strip was also planted in the fumigated area adjacent to, and 2 $m$ away from the inoculum concentration plots to accommodate the positive control plots, which were not fenced in this nursery. In addition, a 91-m-long eight-row strip of Cheyenne was planted outside the fumigated area adjacent to the nursery.

The efficacy of the fumigation was tested by placing samples of teliospore contaminated soil in small nylon bags at 0,5 , and $10 \mathrm{~cm}$ beneath the soil surface in three locations beneath the tarp, and one location outside the tarp to serve as a control. After fumigation, teliospores were extracted from the samples and assayed for viability as described by Goates and Peterson (6).

Several efforts were made in Logan to avoid recontamination of the soil in the fumigated area. All equipment used inside the plot was washed thoroughly with a steam cleaner prior to unloading it into the fumigated area. The equipment did not leave the fumigated area until planting and marking plots was completed. When walking in and out of the fumigated area was required, shoes were either changed or covered with plastic bags. To assure no viable teliospores were present on the seed prior to planting, it was pretreated with $1.6 \%$ aqueous $\mathrm{NaOCl}$ for $10 \mathrm{~min}$, rinsed with water for $15 \mathrm{~min}$, and then air-dried. The initial seed for the Kansas experiments was also given this treatment. Seed harvested in Kansas from disease-free plots was used in later seasons.

In the spring, during April, the fences surrounding initial inoculation plots were removed and the crop was allowed to grow to maturity. Plots were given about 30 units of nitrogen fertilizer in the spring. In most years, the nurseries in Kansas were sprayed in the spring with sulfonyl-urea herbicide at labeled rates to inhibit growth of broadleaf weeds. The nurseries were not given supplemental irrigation. After harvest, fields were disked once or twice during the summer to reduce crop residue and destroy volunteer wheat. Plots were disked again and harrowed for seed bed preparation just prior to planting.

Disease evaluation and data analysis. After plant maturity at both locations, all spikes were visually examined for disease and the total number of diseased spikes per plot was recorded. If any diseased spikes occurred in the plots in Kansas, the spikes were picked, crushed by hand, and then placed back into the same place the infected plant was found. To determine the percent diseased spikes in the plots, the total number of spikes within the plot was estimated by counting the number of spikes in ten $91-\mathrm{cm}$ sections of row centered along diagonal transects of the plot. The mean number of spikes per meter of row was calculated and then multiplied by the total number of meters of row within the plot. The mean and standard deviation of percent infected spikes in the four replicated plots was calculated. The percent infection in the highly infected positive control plots in Logan was visually estimated. Disease incidence data from the Logan nursery was analyzed with SAS GENMOD to fit a generalized linear model to the binomial response of percent infection.

\section{Results}

Plant stand and establishment. All nurseries were at approximately the three-leaf stage when they became dormant in early winter. All nurseries in Kansas had good to excellent plant stands during the growing season in each year of the experiments. In the Logan nursery, there was slight damage evident in most plots from snow mold, caused by Microdochium nivale, in early spring, and substantial snow mold damage in three plots in one block where the plant stands in the $0.88,88.4$, and 884 spores $/ \mathrm{cm}^{2}$ treatments had approximately 25 to $50 \%$ loss. However, the stands in these plots were considered sufficient to obtain adequate disease data for the experiment and they were included in the results. Plant stands in the other plots in Logan were excellent.

Disease evaluations. In the Kansas 2001-2002 inoculated nursery, dwarf bunt was not induced and did not occur during the five following seasons after the susceptible cultivar Cheyenne was planted in the nursery area without further inoculation (Table 1).

In the 2002-2003 inoculated nursery, trace amounts of disease were induced at inoculum rates of 884 spores $/ \mathrm{cm}^{2}$ or above. At the 884 spores $/ \mathrm{cm}^{2}$ rate, a single bunted spike occurred in one of the four replicates, whereas the other replicates at this rate had no diseased spikes. At the highest test rate of 8,840 spores $/ \mathrm{cm}^{2}$, there was disease in all four replicates ranging from 2 to 18 infected spikes per plot. It was estimated that individual plots each contained approximately 11,300 total spikes. The four positive control plots had from 0.25 to $1.24 \%$ infected spikes, and it was estimated these smaller plots had approximately 2,800 total spikes. After incorporating the infected spikes directly into the respective plots by hand, as described previously, followed by cultivation, approximately 2 months of fallow, seed bed preparation, and replanting the nursery area in the fall of 2003 with Cheyenne, traces of bunt occurred, but only in the area of two replicates of positive control plots that had disease the previous year. This was the only time disease carryover was observed during the study. Disease did not occur in any part of this nursery area during the following three seasons (Table 1).

In the 2003-2004 inoculated nursery, trace amounts of disease were induced at the rate of $884 \mathrm{spores} / \mathrm{cm}^{2}$ and above, but infection was at higher levels than in the 2002-2003 nursery. At the 884 spores $/ \mathrm{cm}^{2}$ rate, all four replicated plots had some bunted spikes ranging from 1 to 7 , and the highest test rate of 8,840 spores $/ \mathrm{cm}^{2}$ had from 36 to 55 bunted spikes in the four replicates. The total number of spikes per plot in this season was estimated to be 16,100 in the large plots and 4,000 in the small positive control plots. The positive control plots had 0.72 to $1.27 \%$ infected spikes. Planting Cheyenne into the nursery area for three consecutive seasons afterward resulted in no disease (Table 1).

The environment was highly conducive to disease development in the Logan experiment in 2000-2001, as evidenced by 98 to $99 \%$ diseased spikes in the four positive control plots. Methyl bromide fumigation prior to planting the plots killed more than $99.99 \%$ of teliospores in the soil samples buried at 0,5 , and $10 \mathrm{~cm}$ deep in three locations beneath the tarp in a fumigation efficacy test, whereas nonfumigated controls had more than $70 \%$ germination. A slight trace of infection occurred in all of the uninoculated control plots (mean 0.07\%) (Table 2). Infection in the uninoculated control plots in Logan may have been due to rain splashing and/or wind moving contaminated soil from the surrounding field into the plot area after the fumigation, or due to incomplete decontamination by the fumigation. Portions of the uninoculated 91-m-long eight-row strip planted outside the fumigated area had nearly $100 \%$ infection, demonstrating the high level of natural inoculum in the soil at the site, and the possibility of plot contamination from surrounding contaminated field soil.

Variable trace amounts of infection occurred in the plots in Logan inoculated with 0.88 and 8.8 teliospores $/ \mathrm{cm}^{2}$ (Table 2). In- 
oculation with a minimum of 88 teliospores $/ \mathrm{cm}^{2}$ was required to induce at least $1 \%$ infection. The two highest test rates had severe infection with means of 40.1 and $83.4 \%$ infected spikes. Although the two lowest inoculum concentrations had more mean infected spikes than the uninoculated control plots, data analysis showed no statistically significant differences in infection between these plots and the noninoculated control. There was considerable variability among replications at the 884 teliospores $/ \mathrm{cm}^{2}$ rate, primarily due to low infection in the replicate block that had snow mold damage.

Snow cover. Hourly soil surface temperature data for each season and nursery site were graphed to determine periods and durations of snow cover and stable temperatures (Figs. 3 to 5). Soil surface temperature data were compared to daily precipitation data from the Rossville weather station and were found to correlate well with our snow cover assumptions. In all cases, when a precipitation event occurred and soil temperatures were below freezing, the hourly soil surface temperatures remained below freezing throughout the day and night with no fluctuation above freezing, suggesting the presence of insulating snow cover. Once temperatures above freezing occurred, day and night soil temperatures began to fluctuate significantly, suggesting the absence of the snow cover.

Direct field observation and the soil surface temperature data (Fig. 5) show that the first significant snowfall at the Logan site occurred on 2 November 2000 and snow remained persistent until approximately 11 March 2001. This was a total of 129 days of continuous snow cover during which temperatures ranged from

Table 1. Incidence of dwarf bunt in the susceptible cultivar Cheyenne in Rossville, KS after inoculation of soil in three nursery sites with different concentrations of Tilletia contraversa teliospores ${ }^{\mathrm{y}}$

\begin{tabular}{|c|c|c|c|c|c|c|c|c|}
\hline \multirow{3}{*}{$\begin{array}{l}\text { Nursery site } \\
\text { Crop year }\end{array}$} & & \multicolumn{7}{|c|}{$\%$ Bunted spikes at no. of spores $/ \mathrm{cm}^{2}$} \\
\hline & & \multicolumn{6}{|c|}{ Inoculation plots } & \multirow{2}{*}{$\begin{array}{c}\text { Control } \\
\mathbf{8 8 , 4 0 0}\end{array}$} \\
\hline & & $\mathbf{0}$ & 0.88 & 8.8 & 88.4 & 884 & 8,840 & \\
\hline \multicolumn{9}{|c|}{ Site $1-2001-02$ inoculation } \\
\hline 2001-02 & $\begin{array}{l}\text { Mean }^{z} \\
\text { SD }\end{array}$ & 0 & 0 & 0 & 0 & 0 & 0 & 0 \\
\hline $2002-03$ & $\begin{array}{l}\text { Mean } \\
\text { SD }\end{array}$ & 0 & 0 & 0 & 0 & 0 & 0 & 0 \\
\hline 2003-04 & $\begin{array}{l}\text { Mean } \\
\text { SD }\end{array}$ & 0 & 0 & 0 & 0 & 0 & 0 & 0 \\
\hline 2004-05 & $\begin{array}{l}\text { Mean } \\
\text { SD }\end{array}$ & 0 & 0 & 0 & 0 & 0 & 0 & 0 \\
\hline $2005-06$ & $\begin{array}{l}\text { Mean } \\
\text { SD }\end{array}$ & 0 & 0 & 0 & 0 & 0 & 0 & 0 \\
\hline 2006-07 & $\begin{array}{l}\text { Mean } \\
\text { SD }\end{array}$ & 0 & 0 & 0 & 0 & 0 & 0 & 0 \\
\hline \multicolumn{9}{|c|}{ Site $2-2002-03$ inoculation } \\
\hline $2002-03$ & $\begin{array}{l}\text { Mean } \\
\text { SD }\end{array}$ & 0 & 0 & 0 & 0 & $\begin{array}{l}0.002 \\
0.005\end{array}$ & $\begin{array}{l}0.062 \\
0.066\end{array}$ & $\begin{array}{l}0.744 \\
0.414\end{array}$ \\
\hline 2003-04 & $\begin{array}{l}\text { Mean } \\
\text { SD }\end{array}$ & 0 & 0 & 0 & 0 & 0 & 0 & $\begin{array}{l}0.073 \\
0.089\end{array}$ \\
\hline 2004-05 & $\begin{array}{l}\text { Mean } \\
\text { SD }\end{array}$ & 0 & 0 & 0 & 0 & 0 & 0 & 0 \\
\hline $2005-06$ & $\begin{array}{l}\text { Mean } \\
\text { SD }\end{array}$ & 0 & 0 & 0 & 0 & 0 & 0 & 0 \\
\hline 2006-07 & $\begin{array}{l}\text { Mean } \\
\text { SD }\end{array}$ & 0 & 0 & 0 & 0 & 0 & 0 & 0 \\
\hline \multicolumn{9}{|c|}{ Site 3 - 2003-04 inoculation } \\
\hline 2003-04 & $\begin{array}{l}\text { Mean } \\
\text { SD }\end{array}$ & 0 & 0 & 0 & 0 & $\begin{array}{l}0.017 \\
0.018\end{array}$ & $\begin{array}{l}0.282 \\
0.058\end{array}$ & $\begin{array}{l}0.998 \\
0.234\end{array}$ \\
\hline 2004-05 & $\begin{array}{l}\text { Mean } \\
\text { SD }\end{array}$ & 0 & 0 & 0 & 0 & 0 & 0 & 0 \\
\hline $2005-06$ & $\begin{array}{l}\text { Mean } \\
\text { SD }\end{array}$ & 0 & 0 & 0 & 0 & 0 & 0 & 0 \\
\hline 2006-07 & $\begin{array}{l}\text { Mean } \\
\text { SD }\end{array}$ & 0 & 0 & 0 & 0 & 0 & 0 & 0 \\
\hline
\end{tabular}

${ }^{y}$ Inoculum consisted of a mixture of isolates originating from throughout the northwestern United States. After initial inoculation of soil, the only inoculum added to plots was from diseased plants. Diseased spikes produced were crushed by hand and placed back into the plots where they were produced.

${ }^{\mathrm{z}}$ Mean of four replicate eight-row plots $2.8 \mathrm{~m}$ wide $\times 9.75 \mathrm{~m}$ long, and $2.8 \times 9.75 \mathrm{~m}$ positive control plots.

Table 2. Incidence of dwarf bunt in the susceptible cultivar Cheyenne in Logan, UT after inoculation with different concentrations of Tilletia contraversa teliospores $^{\mathrm{w}}$

\begin{tabular}{|c|c|c|c|c|c|c|c|}
\hline & \multicolumn{7}{|c|}{$\%$ Bunted spikes ${ }^{x}$ at no. of teliospores $/ \mathrm{cm}^{2}$} \\
\hline & \multicolumn{6}{|c|}{ Inoculation plots ${ }^{y}$} & \multirow{2}{*}{$\begin{array}{c}\text { Control }^{\mathrm{z}} \\
\mathbf{8 8 , 4 0 0} \\
\end{array}$} \\
\hline & $\mathbf{0}$ & 0.88 & 8.8 & 88.4 & 884 & 8,840 & \\
\hline Mean & $0.07 \mathrm{a}$ & $0.28 \mathrm{a}$ & $0.16 \mathrm{a}$ & $2.88 \mathrm{~b}$ & $40.84 \mathrm{c}$ & $83.39 \mathrm{~d}$ & 98.3 \\
\hline SD & 0.03 & 0.24 & 0.11 & 1.13 & 21.84 & 4.5 & 0.5 \\
\hline
\end{tabular}

${ }^{\mathrm{w}}$ Inoculum consisted of a mixture of isolates originating from throughout the northwestern United States. The plot area was fumigated with methyl bromide prior to planting to kill teliospores naturally present in the soil.

${ }^{x}$ Means followed by the same letter are not significantly different based on analysis with SAS GENMOD to fit a generalized linear model to the binomial response of percent infection.

${ }^{\mathrm{y}}$ Mean of four replicates of eight 9.75 -m-long rows.

${ }^{\mathrm{z}}$ Mean of four replicates of eight 3-m-long rows planted outside the fumigated area. 
-0.04 to $-7.58^{\circ} \mathrm{C}$ and averaged $-2.93^{\circ} \mathrm{C}$ (std. dev. 1.42). These conditions induced the high levels of disease in the Logan nursery.

In Rossville, snow cover ranged from periods of 1 to 31 days during the 6 years as illustrated in the temperature graphs. The total numbers of days of snow cover in Rossville for each season from 2001 to 2006 were $10,39,49,35,29$, and 40, respectively; however the snow was not continuous (Figs. 3 and 4). The highest levels of infection observed at Rossville occurred during the 20032004 season (Table 1). This coincides with the season with the most days of snow cover at the site (Fig. 3C), and it was the only season disease carryover occurred. The season with the fewest days of snow cover was 2001-2002 (Fig. 3A), which was the only season that the initial inoculation resulted in no disease. There were only 4 and 10 days less snow cover in 2004-2005 and 2005-2006, respectively, than in the 2002-2003 season. The total days of snow cover in 2006-2007 was greater (1 day) than in 2002-2003, and that season also saw general precipitation greater than twice that of the 2003-2004 season. The 2002-2003 season had the lowest level of general precipitation, despite having adequate periods of snow cover to support disease.

\section{Discussion}

These experiments demonstrated that low levels of dwarf bunt can be induced in an area outside of the long-recognized historical boundaries for the disease when using high levels of inoculum in
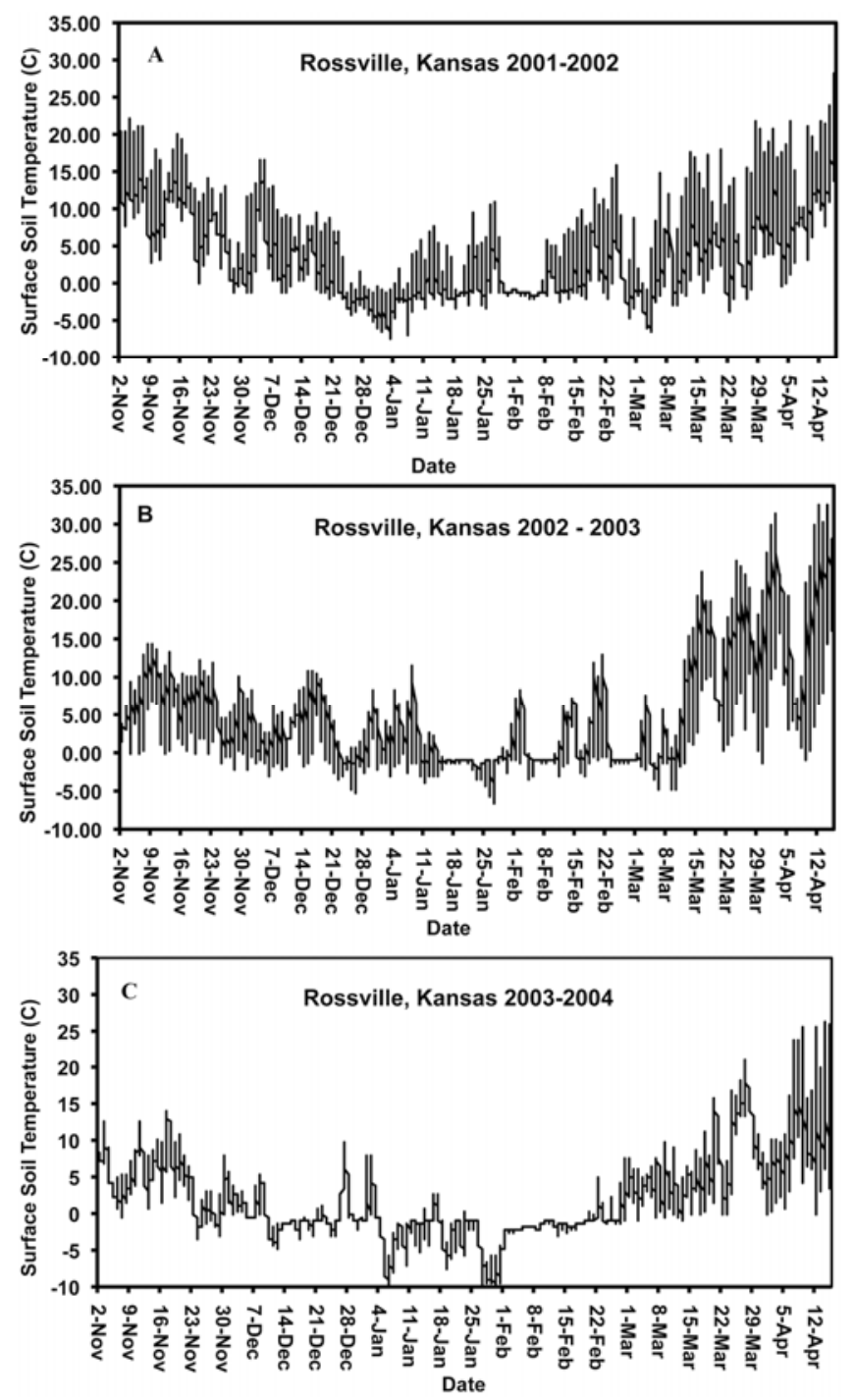

Fig. 3. Hourly soil surface temperature recorded from the time of fall planting in $\mathbf{A}$, 2001, B, 2002, and C, 2003, in Rossville, KS for comparison with temperature data recorded at Logan, UT in 2000. combination with a highly susceptible wheat variety that was managed to be in the most susceptible condition. However, even though dwarf bunt was induced in two of three nurseries in Kansas, and the teliospores produced were incorporated into the soil, the disease disappeared rather rapidly within one or two seasons. This is likely due to the decline in the number of viable teliospores to an insufficient concentration to induce disease in this marginal environment.

The Kansas results are consistent with the predictions of the Dwarf Bunt Geophytopathological Model (TCK-GM). Fifteen years of historical weather data from the PRC, Kansas, Oklahoma, and Texas showed that persistent snow cover and/or temperatures favorable to $T$. contraversa teliospore germination and host infection occurred in less than 5\% of the years and would not support disease establishment (11). In contrast, areas where the disease was known to occur in the United States had disease-conducive conditions during 30 to $95 \%$ of the years examined. The TCK-GM disease introduction scenario requires 42 cumulative days of snow cover while soil surface temperatures remain between 2 and $10^{\circ} \mathrm{C}$. In the Kansas plots, only the 2003-2004 season had more than 42 days of snow cover (Fig. 3), which coincided with the highest lev-
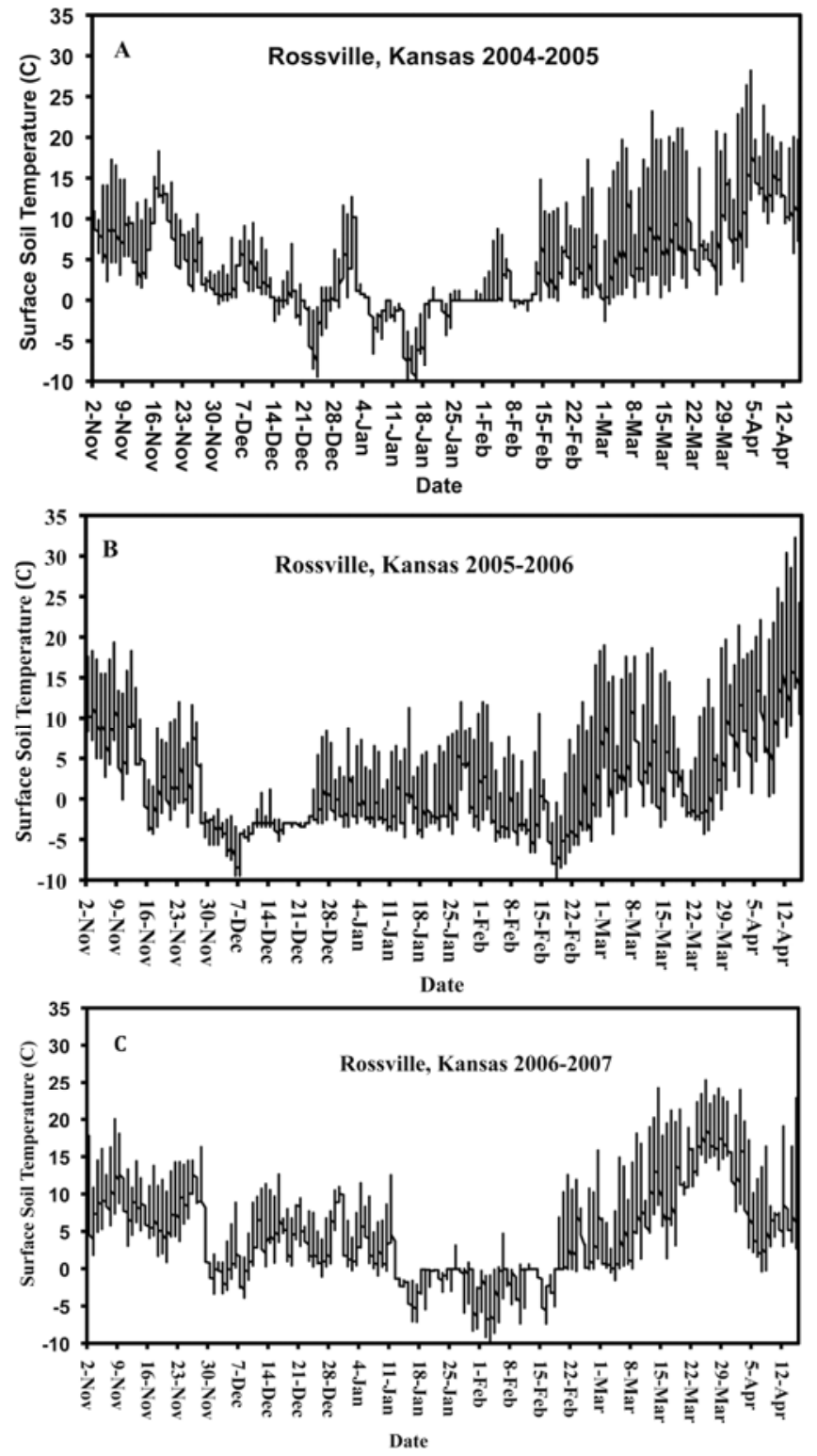

Fig. 4. Hourly soil surface temperature recorded from the time of fall planting in $A$, $2004, \mathbf{B}, 2005$, and C, 2006, in Rossville, KS for comparison with temperature data recorded at Logan, UT in 2000. 
els of disease and the only year that carryover from a prior year occurred (Table 1). The carryover occurred at slight trace levels in positive control plots that had the highest rate of initial inoculum plus the addition of diseased spikes produced the prior year. The 2001-2002 season had the least snow cover (10 days), which coincided with the only year with zero incidence in all plots after the initial inoculation. The 2006-2007 season had 40 cumulative days of snow cover, and theoretically should have been the second most favorable year for dwarf bunt, yet no disease was detected in any plot in any nursery. In all cases, dwarf bunt incidence and days with snow cover in Kansas were much lower than in Utah plots, where there were 129 favorable days with snow cover and disease incidence was nearly $100 \%$ in the positive control plots (Table 2). Thus, the association between days of snow cover and dwarf bunt incidence appears to hold true in Kansas as elsewhere.

Logan was chosen as a disease-conducive area to compare with the results in Kansas because it has some of the most reliable disease-conducive winter climate of anywhere in the United States where dwarf bunt occurs. The year the tests were conducted in Logan was certainly one of the best years for disease-conducive climatic conditions, demonstrating the full potential of inoculum at the different concentrations used in these experiments. However, in some seasons snow cover in annual screening nurseries in Logan is inconsistent, resulting in positive control plots of Cheyenne achieving only 3 to $12 \%$ infection or less, despite high levels of natural inoculum in the soil in addition to high levels of artificial inoculum (B. J. Goates, unpublished). This is another example that snow cover is a critical factor in disease development.

The data suggest that a steep decline in soilborne inoculum potential from year to year was another important factor in the failure to establish dwarf bunt in the Kansas plots. Comparison of inoculation treatments across nursery sites in 2002-2003 showed detectable disease at the three highest inoculum doses with the current year's inoculum, but not the previous year's. This suggests that inoculum potential in the previous year's inoculum declined by one to two orders of magnitude. The decline in inoculum potential could be due, in part, to teliospores that germinated but failed to successfully infect. Teliospores of $T$. contraversa germinate in vitro after incubation for 3 to 10 weeks on moist soil or agar at temperatures between -2 and $10^{\circ} \mathrm{C}$. The optimal temperature for germination is from 3 to $8^{\circ} \mathrm{C}$. Most isolates reach maximum germination percentage after 6 to 8 weeks incubation at optimal temperatures (7). Continuous snow cover at Logan lasted for over 3 months with surface soil temperatures never rising above $0^{\circ} \mathrm{C}$ during that time. In Kansas, teliospores were subjected to temperatures conducive to germination during an approximate 2-month period during December and January, which should have been sufficient for teliospores to begin germination. However, during that time plots were subjected to fluctuating levels of soil moisture, temperature, and snow cover.

Common tillage after harvest and disking and harrowing for seed bed preparation in late summer tend to distribute teliospores

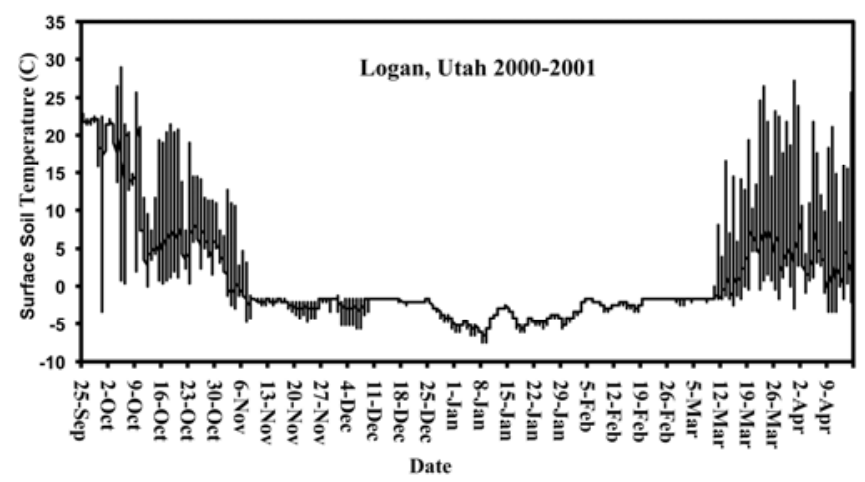

Fig. 5. Hourly soil surface temperature recorded from the time of fall planting in 2000 in Logan, UT for comparison with temperature data recorded at Rossville, KS between 2001 and 2006 . throughout the soil profile, diluting the concentration at the soil surface (1). The artificial reintroduction of fresh inoculum from the bunted spikes produced a more concentrated inoculum than would occur during normal harvest with a combine, which would have caused spores to become much more dispersed. Thus, the handling of diseased spikes in this manner likely had the potential to produce a more severe reaction than would be expected in normal harvesting operations.

The incorporation of infected spikes, which usually have all kernels replaced with sori, added a considerable amount of fresh inoculum to the soil in plots in Kansas. The handling of diseased spikes in this manner was done to ensure the experiment was a fair test of the ability of the pathogen to establish over multiple years. Individual dwarf bunt sori (bunt balls) contain approximately 4 to 6 $\times 10^{6}$ individual teliospores (B. J. Goates, unpublished). Assuming there were 30 kernels per spike in cultivar Cheyenne, there would be a maximum of $1.8 \times 10^{8}$ teliospores per bunted spike. In the year prior to detection of disease carryover, the positive control plots had a maximum of 35 infected spikes $(1.24 \%)$ in a $7.84 \mathrm{~m}^{2}$ area. That would equate to an average density of $8 \times 10^{4}$ teliospores $/ \mathrm{cm}^{2}$ returned to the plot.

During the original inoculations in this experiment, the teliospores were placed at the ideal location of the soil surface. Such high levels of inoculum at the soil surface under natural field conditions could come only from a previous crop with a high level of disease incidence. But, a natural high level of disease could result only from high levels of natural inoculum that are very unlikely in such marginal climates. This indicates that even if the disease could become sufficiently established to occur in rare years with exceptional disease-conducive climatic conditions, it is likely the disease would not be severe due to low inoculum levels.

Our results support the conclusions of the risk assessment model for the importation of U.S. milling wheat containing T. contraversa (11), especially as applied to the PRC. Furthermore, the results substantiate the 1999 Agreement on U.S.-China Agricultural Cooperation which recognized the low level of risk to China's wheat production associated with the importation of U.S. milling wheat containing teliospores. The tolerance level of $3 \times 10^{4}$ teliospores per $50 \mathrm{~g}$ of wheat that is stated in the agreement is equivalent to the lowest inoculum concentration used in this study. The information presented here supports the contention that the present geographic distribution of dwarf bunt of wheat is a result of the narrow environmental requirements for disease establishment, rather than lack of introduction opportunities.

\section{Acknowledgments}

The assistance of Charles Clark, William Riley, and Elburn Parker for field preparation, planting, and maintenance at the Rossville Experiment Station was greatly appreciated. We thank David Hole, Utah State University, for assistance with site preparation and maintenance at Logan. Peng Jinhou and Zhou GuoLiang of the Quarantine Bureau of the People's Republic of China provided input and assistance during planting, inoculation, and disease evaluation in the Logan nursery. The work in Kansas would not have been possible without the cooperation of Kansas State University, the Kansas Wheat Commission, and the Kansas Department of Agriculture and their confidence in the pest risk assessment process. The USDA Animal Plant Inspection Service is thanked for their extra efforts in the permitting for this work. We thank Bruce Mackey, USDAARS, for statistical analysis of the data from the Logan nursery as well as Deborah Glenn-Parrish and Kathy Fronda, USDA-ARS, for technical and field assistance. We acknowledge Robert Stefanski, WMO, Geneva, Switzerland for the U.S./China climatic comparisons. We also thank Wilda Martinez, USDA$\mathrm{ARS}$, for assistance and encouragement during the project.

\section{Literature Cited}

1. Allen, T. W., Workneh, F, Steddom, K. C., Peterson, G. L., and Rush, C. M 2008. The influence of tillage on dispersal of Tilletia indica teliospores from a concentrated point source. Plant Dis. 92:351-356.

2. Becker, G. S., and Hanrahan, C. E., Cong. 2002. Research Serv. Report for Congress, Order Code RS21292, Agriculture: U.S.-China Trade Issues (Updated October 16, 2002) available at http://www.nationalaglawcenter.org/ assets/crs/RS21292.pdf

3. Durán, R., and Fischer, G. W. 1961. The Genus Tilletia. Washington State University Press, Pullman. 
4. Goates, B. J. 1992. Control of dwarf bunt of wheat by seed treatment with Dividend 3FS. Fungic. Nematicide Tests 47:264.

5. Goates, B. J. 1998. Host resistance to dwarf bunt of wheat. Pages 317-326 in: Bunts and Smuts of Wheat: An International Symposium. August 17-20, 1997. Research Triangle Park, NC, USA. V. S. Malik and D. E. Mathre, eds. North American Plant Protection Organization, Ottawa, Canada.

6. Goates, B. J., and Peterson, G. L. 1999. Relationship between soilborne and seedborne inoculum density and the incidence of dwarf bunt. Plant Dis. 83:819-824.

7. Hoffmann, J. A. 1982. Bunt of wheat. Plant Dis. 66:979-986.

8. Hoffmann, J. A., and Purdy, L. H. 1967. Effect of stage of development of winter wheat on infection by Tilletia controversa. Phytopathology 57:410413.

9. Keener, T. K., Stougaard, R. N., and Mathre, D. E. 1995. Effect of winter wheat cultivar and difenoconazole seed treatment on dwarf bunt. Plant
Dis. 79:601-604.

10. Meiners, J. P., Kendrick, E. L., and Holton, C. S. 1956. Depth of seeding as a factor in the incidence of dwarf bunt and its possible relationship to spore germination on or near the soil surface. Plant Dis. Rep. 40:242-243.

11. Peterson, G. L., Whitaker, T. B., Stefanski, R. J., Podleckis, E.V., Phillips, J. G., Wu, J. S., and Martinez, W. H. 2009. A risk assessment model for importation of United States milling wheat containing Tilletia contraversa. Plant Dis. 93:560-573.

12. Sitton, J. W., Line, R. F., Waldher, J. T., and Goates, B. J. 1993. Difenoconazole seed treatment for control of dwarf bunt of winter wheat. Plant Dis. 77:1148-1151.

13. Trione, E. J. 1982. Dwarf bunt of wheat and its importance in international wheat trade. Plant Dis. 66:1083-1088.

14. Tyler, L. J., and Jensen, N. F. 1958. Some factors that influence development of dwarf bunt in winter wheat. Phytopathology 48:565-571. 